\title{
Dispelling the Myths about the Effectiveness of the Zimbabwe Open University Primary School Trained Teacher in the Instructional Process: Echoes from the Frontline
}

\author{
Mubika, Augustine, K. ${ }^{1^{*}}$, Richard Bukaliya ${ }^{2}$ \\ ${ }^{I}$ Zimbabwe Open University, Mashonaland West Region, Zimbabwe \\ ${ }^{2}$ Zimbabwe Open University, Mashonaland East Region, Zimbabwe
}

*Corresponding Author: Mubika, Augustine, K, Zimbabwe Open University, Mashonaland West Region, Zimbabwe

\begin{abstract}
The acute shortage of teachers in Zimbabwe and indeed elsewhere has been responded to innovative approaches that have seen open and distance learning being adopted to quell the under supply of the teachers. While some of the innovations have been positively received by the communities, training teachers through ODL has received mixed feelings (Dede, 1996; Harrison, 2001). It is from this view point that this study sought to establish the effectiveness of the teachers trained through the Zimbabwe Open University Primary School Teachers Training programme from the point of view of the education officers, heads of schools, Civil Service Commission inspectors and the students trained through ODL at ZOU. The present study was a case study of Mashonaland West province in which two districts were randomly selected. The study adopted in-depth interviews as data collection instruments. The study sample was 40 and consisted of 20 ZOU Diploma in Education (Primary), 10 school heads, 8 Education officers and 2 Civil Service Commission inspectors. Results from the study show that there was acceptance among respondents that the theory taught to the ODL student teacher is being put into practice. ODL Diploma students were thorough in the general classroom management of their work which is enhanced by frequent visits by senior teachers at their individual schools of work and Teaching Practice visits by ZOU lecturers. Most teachers were up to scratch in their documentation especially in scheming which is compulsory in most schools and this has been necessitated by the visits by senior school authorities and lecturers from ZOU which help in many ways in improving scheming, planning lessons and evaluation. Most teachers are capable of handling their lessons effectively as seen in narrative reports that spoke so well on lesson introductions, teaching strategies, instructional media use and concept and skills development.
\end{abstract}

Key words: Effectiveness, Primary school teacher training programme, Staff shortages

\section{BACKGROUND TO THE STUDY}

The training of teachers in Zimbabwe has been through a number of initiatives. The teachers` colleges affiliated to the University of Zimbabwe have been the most predominant in the churning out of both primary and secondary school teachers. On one hand, there has been the ZINTEC programme that accorded more time to students to learn while on teaching practice. On the other, the conventional system was tailor made to offer students more time in residential courses than on teaching practice. However, there has been a shift from this arrangement as all primary school teacher training colleges have reverted to the ZINTEC type of training. Amidst all this, the number of teachers has failed to meet demand; hence other alternatives had to be sought. The Zimbabwe Open University (ZOU) during the July-December 2006 semester introduced the Diploma in Education (primary) programme to train primary school teachers in order to address the staff shortages in Zimbabwe amidst the economic meltdown that saw Zimbabwe lose a lot of skilled manpower to other countries for greener pastures.

After operating and churning out a sizeable number of graduates to fill in the vacated post, the programme experienced challenges as some stakeholders in the education sector branded the initiative as being ineffective and of poor quality resulting in the programme's suspension by Zimbabwe Council for High Education (ZIMCHE). It was argued that the programme lacked certain aspects that were very significant in a teacher training programme. Among the shortcomings it was argued that the 
programme could have incorporated the main subject area as well as the basic courses such as the teaching practice component that required better coordination.

With that in mind, the graduates therefore had to make do with temporary teaching posts based on their ordinary level qualification. The Public Service Commission, which is the employer of all government workers refused to recognize the diploma qualification on the basis of the disqualification by ZIMCHE. However, after the recommendations by ZIMCHE were factored into the programme, the suspension of the diploma was eventually lifted in 2015, paving way for the enrollment of Intake 10 .

The issue in this study, however, is the extent to which the students who graduated before the suspension were effective in the discharge of their duties regardless of them being labeled unfit to practice as qualified teachers. This study sought the point of view the education officers, heads of schools, Civil Service Commission inspectors in one selected province of Zimbabwe, where the students were actively involved in teaching as temporary teachers despite holding ZOU diplomas. The students trained through ODL at ZOU had their opinions sought on the issue.

\section{RESEARCH QUESTIONS}

The following were the research questions which the study aimed at answering:

1. How effective are the teachers trained through ODL effectively carrying out their duties as classroom practitioners?

2. To what extent are teachers trained through the ODL teacher training programme effective in the administration of schools?

3. How are the teachers rated in different personal dimensions?

4. What is the extent of the teachers' involvement in extra curricula activities?

\section{REVIEW OF RELATED LiTERATURE}

The issue of open and distance learning (ODL) has been quite controversial within certain quarters of the academic fraternity; with some accepting ODL graduates and others not accepting. Thus Open and Distance Learning qualifications have been received with mixed feelings by various stakeholders in spite of ODL's splendid role and increased popularity in various sectors of the economy(Mubika and Bukaliya, 2014).But while the quality of qualifications is put to question(Dede,1996;Harrison,2001) it been proven that there is no significant difference in quality between those degrees and diplomas acquired through ODL and those acquired through a conventional system (Basaza, Milman \& Wright; 2010). This being the case debate, therefore, continues to rage on the superiority of either option over the other. However, in some cases, it is arguments for the sack of just arguing without empirical supporting facts. This is so because in spite of the several empirical studies carried out to juxtapose distance education and traditional face-to-face graduates, distant education graduates continue to be shunned despite the afore-stated studies having established and demonstrated that there is no significant difference between the quality of the two processes (Bazasa, Milman \& Wright, 2010).In a study by Open University of Hong Kong(1999), employers perceived ODL as acceptable and advantageous in terms of staff continuity, ease of personnel management, the degree is immediate workplace application of skills acquired by staff and continuous professional development of staff. In the same study, distance learning was viewed as good as tradition face-to-face mode, thus some employers preferred ODL graduates to enhance professional development. There were 184 employers who indicated that they were employers ODL graduates. They rated them highly on diligence, perseverance, willingness to learn and general job skills. Facts are that though there is worldwide acceptance of ODL products, some prospective employers still doubt the quality and caliber of ODL graduates.

However, according to the same study referred to above, employers were uncertain about whether or not the quality of ODL graduate employees was comparable to graduates of other types of universities. Research conducted by Adams and DeFleur (2005) regarding doctorate graduates indicate that given the choice of selecting job candidates who possessed online(a form of ODL mode) or traditional doctorial degree credentialing, $98 \%$ of 109 employers surveyed preferred to a candidate with a traditional doctoral degree. Flowers and Baltzer (2006) study replicated and conformed the 
study by Adams and Defleur (2005). Findings by Flowers and Baltzer (2006) revealed that employers are less likely to engage a candidate with an ODL doctoral degree for full time position. Guendoo (2008) investigated the acceptability of online degrees amongst 52 administrators of colleges in the United States of America and found out that online degrees were not a hindrance to one's chance for employment. Chaney (2002) also researched on the issue of acceptability of online degrees for employment in eight Midwest pharmaceutical companies and focused on the perception about online degrees those being hired for various positions that mostly require scientific backgrounds. The findings indicated that although all the participants questioned whether the scientific content and labs could be taught online, most of the respondents made no distinction between an online degree and a traditional degree when considering applicants in the hiring process.

Seibold (2007) carried out a study in telecommunications, data systems, insurance, and finance and rental business industries. She establishes that employers still prefer to hire traditional degree holders to degrees obtained through other means although hybrid degrees were gaining acceptability. Carnevale (2007) established that 55\% of 107 employers surveyed indicated that they would select a candidate with a traditional degree over one who has earned a degree through some form of distance education, and $41 \%$ viewed both degrees equally. Reasons advanced by prospective employers for their reticence in accepting ODL degree credentials include the flowing: lack rigour, lack of face-face interactions, increased potential of academic dishonesty, and concerned about online student's true commitment evident from regularly venturing to a college or university physical location. Gunnell (2010) argues that emotional intelligence which represents an ability to validly reason with emotions and to use emotions to enhance thought is said to be enhanced by face-face interaction that a classroom provides. This does not exist in ODL setting.

On the other hand conditions that could influence ODL acceptance in the hiring process were: name reputation of the degree-granting institution, appropriate level type of accreditation, candidate's relevant work experiences, and whether the graduates were considered for promotion within an organization or if they were vying for new positions elsewhere or in a new field (Carnevale, 2005, 2007).

\section{RESEARCH METHOdOLOGY}

The present study is rooted in the qualitative paradigm and as such the case study design was adopted as the main research design. In order to generate data from the participants, the study adopted the indepth interviews and document analysis as data generation instruments. This form of triangulation enabled the researchers to cross validate data. Data were presented qualitatively, through thematic analysis in which citations from the respondents were either verbatim or paraphrased. Some data were presented quantitatively using simple descriptive statistics. To that end, tables and pie charts were used to present data.

\section{Population And SAmple}

The total population for the current study consisted of 121 participants who included school heads, ODL graduates, education officers and Civil Service Commission Inspectors. Being a qualitative study, a small sample of 20 students, 10 school heads, 8 education officers of Makonde and Hurungwe Districts in Mashonaland West Province; and 4 civil service commission inspectors of same districts(Makonde and Hurungwe) was adopted giving a sample size of 42 participants. These were purposively sampled based on their ability to provide the much needed information on the effectiveness of the teachers trained through ODL programme in meeting staff shortages in the province under study. Only heads of schools and education officers who had worked with the ODL graduates from $\mathrm{ZOU}$ were chosen into the purposive sample.

\section{Presentation AND Discussion OF Findings}

\subsection{The Extent to which the Teachers Trained through Odl Effectively Exercise their Duties as Classroom Practitioners}

To help answer the sub problem on how effective the teachers trained through ODL were effectively carrying out their duties as classroom practitioners, the study sought to establish how different aspects 
of the instructional process were being handled by the teachers. Responses were mostly from interviews by heads of schools and through document analysis.

\subsubsection{General Class and Classroom Management}

Heads of schools who were interviewed on various issues to do with the teachers sounded quite positive about the aspect of class and classroom management. Notable responses indicated that the theory taught to the ODL student teacher was being put into practice. Responses were sought for on class and classroom management, scheming, lesson planning and evaluation, lesson delivery, record keeping and quality of work given to learners as per ministry guidelines.

\subsubsection{Class and Classroom Management}

From the responses ODL Diploma students were thorough in the general classroom management of their work. This, the respondents further say was enhanced by frequent visits by senior teachers at their individual schools of work and Teaching Practice visits by ZOU lecturers. One head of school indicated that the class environments were made vey conducive to learning by the teachers. Issues to do with group work, for example, were carried out in a manner such that all learners felt belonging to the groups they were assigned to. Mixed ability groups were formed for the benefit of all learners. Very meaningful work and instructions were provided to learners in groups. Documentary evidence scrutinised by the researchers supported the claims made by the heads. Records of groups and movement among the groups were kept to show who belonged to which group and why.

\subsubsection{Scheming, Lesson Planning and Evaluation}

Document analysis revealed that most of the teachers were up to scratch in their documentation especially in scheming which was compulsory in most schools. Heads` responses also augmented the results from the document perusals in that schemes of work, lesson plans and evaluation were well done and to satisfaction of all supervisors. However, a few reservations were made on evaluations as the teachers in most cases failed to raise issues of concern to the strategies they would follow to improve on the lesson weaknesses. Some three school heads remarked that the visits by senior school authorities and lecturers from Zimbabwe Open University help in many ways in improving scheming, planning lessons and evaluation.

\subsubsection{Lesson Delivery}

Data from interviews as well as document analysis showed that most of the teachers could handle their lessons effectively. Narrative reports on teachers showed the teachers excelling in lesson delivery. Most of those observed teaching did quite well in lesson introductions, teaching strategies, instructional media use and concept and skills development. The supervisors produced very positive reports on the teachers. It was also surprising to note that the assessment sheets for the teachers indicated that they had a very high level of subject mastery. This was despite the fact that the suspension by ZIMCHE of the same programme was necessitated by the lack of a subject component in the teacher development programme. In most observation and assessment forms used to assess the teachers by their school and district supervisors, indications were made that the teachers made use of child centred approaches, in line with modern philosophy of teaching. During interviews it was also noted that most school heads who wanted to improve Grade 7 results and had a Zimbabwe Open University Diploma in Education graduate(s) or a ZOU Diploma student on his/her establishment, would always assign that ZOU Diploma in Education graduate(s) or that Diploma student(s) to the Grade 7 class. Six of the10 School Heads during the processes of this study confirmed this. From further investigations carried out the Grade 7 pass rates at those positively improved.

While the Zimbabwe Civil Service Commission had refused to employ the ZOU Diploma in Education graduates as qualified teachers, the Zimbabwe's Ministry of Primary and Secondary Education them unreservedly temporary teachers. Added to this, the same ministry promoted these ZOU Diploma, though employed as temporary teachers, to senior positions such as Acting TeacherIn-Charge, Acting School Heads, and Acting School Heads as shall be discussed when looking into the responses below. 
Thus ODL qualifications have been received with mixed feelings by various stakeholders in spite of ODL's splendid role increased popularity in various sectors of the economy (Mubika and Bukaliya, 2014). But while the quality of qualifications obtained via distance education have been called to question (Dede, 1996; Harrison, 2001), it has been proven that there is no significant difference in quality between those degrees and diplomas acquired through ODL and those acquired through the conventional system (Basaza, Miman \&Wright 2010).

\subsubsection{Record Keeping}

This area was also equally well done with all recordings efficiently done. Teachers kept with them the social records, remedial records, progress records, attendance registers, among others. A few cases, however, showed that teachers needed to make analysis of the progress records as just recording the marks and ending there did not give a clear picture of the performance. It was advised in the observation sheets by supervisors that there was need to calculate, for example, the pass rates per test or exercise, the average and so on. This area still lacked in most of the progress records.

\subsubsection{Quality of Work Given to Learners as Per Ministry Guidelines}

When ZOU was designing Diploma in Education(Primary) the University had wider consultations the Ministry and such consultations still continue to keep in pace with dynamic changes of the society. Consequently, the quality of work given to learners is on the based on the expectations of the Ministry's expectations and so were responses.

The teachers trained through ODL effectively exercised their duties as classroom practitioners efficiently and effectively. This, the heads of schools, attributed to various variables such as the supervision by University staff and school administration during training, experience as relief teachers during training and the use of high quality modules produced for each of the courses undertaken. One school head spoke highly of the ZOU modules especially Module DEPP102: Professional Studies, which prepared the teachers for the profession.

\subsubsection{Teachers Involved in Administration and Holding Posts of Special Responsibility}

Out of the 20 sampled teachers who were part of the study, 13 were involved in the administration of schools in various capacities. According to other groups of respondents, most of the teachers trained through ODL (but not part of the sample) were holding posts of special responsibility as shown in Figure 1.

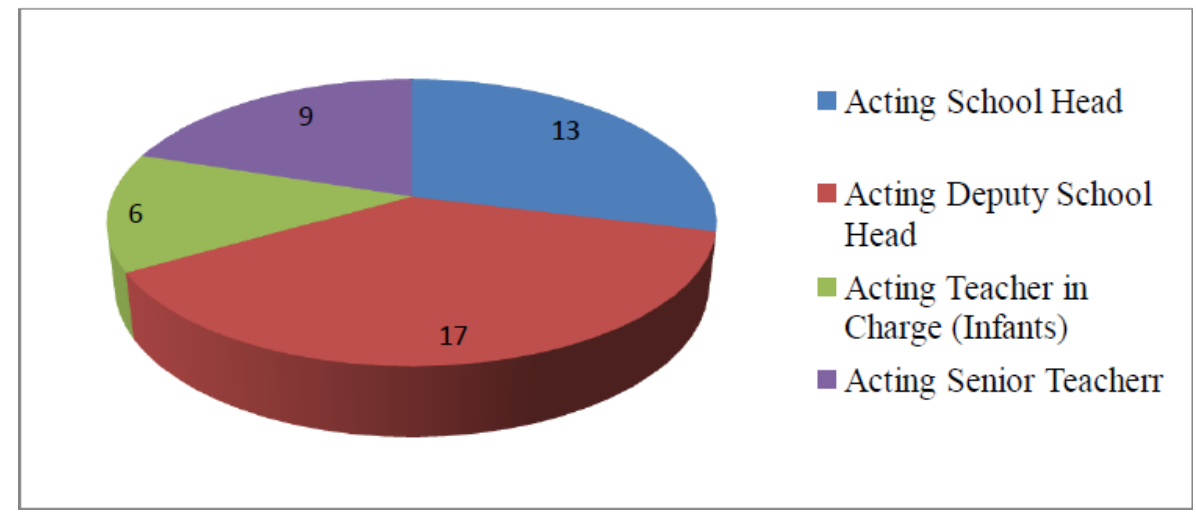

Figure1. Administration and holding posts of special responsibility

Figure 1 shows that 13(65\%) were Acting School heads while some 17(85\%) were Acting Deputy school heads. Acting Teacher in charge (Infants) accounted for 6(30\%) of the teachers while Acting Senior Teachers accounted for some 9(45\%) teachers. Documentation such as Monthly enrolment and Staffing returns produced by the different schools each and every month helped to support the responses from the sample. However, upon further perusal of documents, it was revealed that most of the schools in which the teachers trained through ODL were stationed, were predominantly occupied by lowly qualified staff who held at most the Diploma in Education or its equivalent, the Certificate in Education. Be that it may, it was a very positive achievement for the ODL trained teachers to have to be prioritised over and above others from elsewhere. 
Dispelling the Myths about the Effectiveness of the Zimbabwe Open University Primary School Trained Teacher in the Instructional Process: Echoes from the Frontline

\subsubsection{How Effective Teachers Are in the Administration of Schools}

After establishing that there were ODL graduate teachers holding posts, it was prudent for the study to establish the extent to which they were effective in executing their administrative functions. Table 1, below

Table1. How effective teachers are in the administration of schools $(N=40)$

\begin{tabular}{|l|l|l|l|l|}
\hline \multicolumn{1}{c|}{ Administration aspect } & \multicolumn{2}{c|}{ Effective } & \multicolumn{2}{c|}{ Not effective } \\
\cline { 2 - 5 } & No & \% & No & $\%$ \\
\hline Resource mobilisation & 36 & 90 & 4 & 10 \\
\hline Public relations & 38 & 95 & 2 & 5 \\
\hline Staff development programmes & 23 & 58 & 17 & 42 \\
\hline Supervision & 33 & 83 & 7 & 17 \\
\hline Planning and co-ordination & 35 & 88 & 5 & 12 \\
\hline
\end{tabular}

Table 1 indicates that $36(90 \%)$ of the respondents thought that the teachers were effective in resource mobilization whereas only $4(10 \%)$ indicated these teachers were not effective in resource mobilisation. A majority of $38(95 \%)$ indicated that the teachers were effective in public relations. Only $2(5 \%)$ thought otherwise. When asked whether the teachers were effective in staff development programmes, 23(58\%) were very positive unlike a minority of 17 who thought otherwise. On supervision, $33(83 \%)$ indicated the teachers trained through the ZOU ODL mode were very effective. Another 35(88\%) indicated that the ZOU teachers were effective in planning and co-ordination.

The above findings go on to show that there is general agreement among respondents that the ODL trained teacher was very much effective in the administration of schools. However, issues to do with staff development still needed some attention as the teachers needed to upgrade their professional qualifications and at the same time gain hands on experience before they could of much use in the staff development programmes at school, cluster and provincial level.

\subsubsection{Teachers`Personal Dimensions}

It was also prudent to establish the levels of teachers personal dimensions. Heads of schools were asked to rate the dimensions on a sliding scale that had five levels, 1 being the lowest level and 5 the highest. The following figure presents the findings that are presented as average ratings for all the teachers.

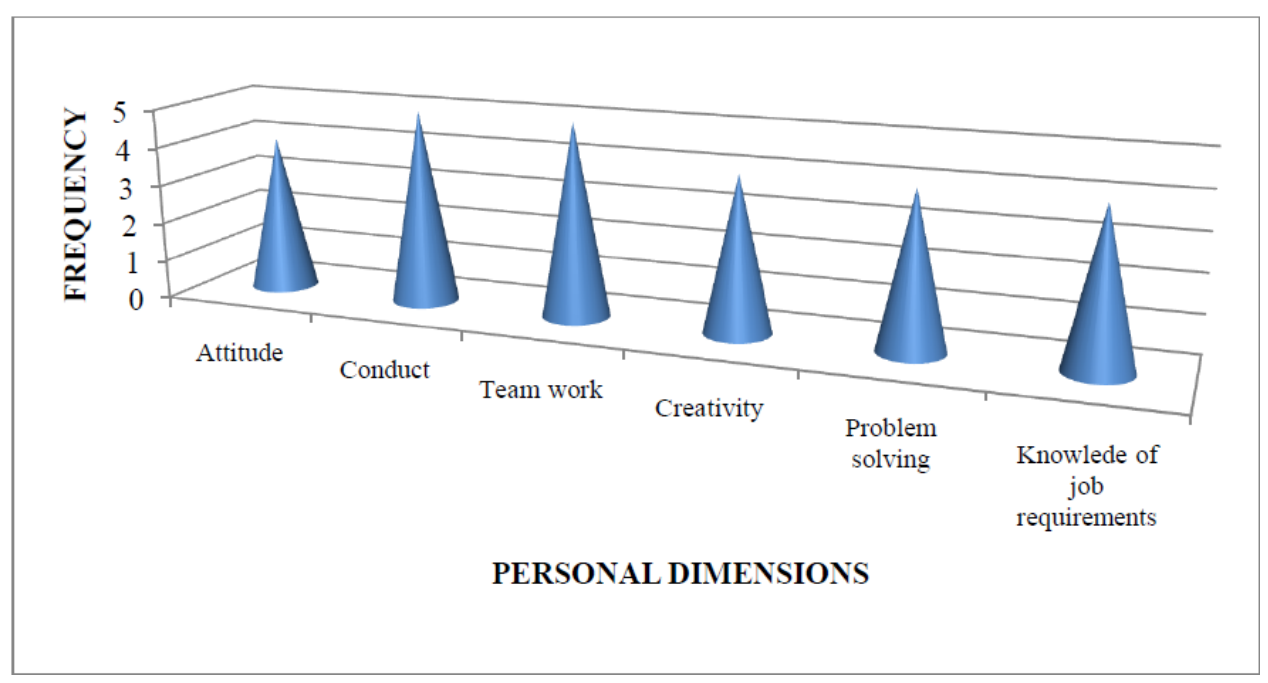

Figure2. Personal dimensions of the teachers

From figure 2, it can be noted that attitude had an average rating of 4 the same for creativity, problem solving and knowledge of job requirements. According to some four school heads, creativity was seen in some of the teachers who had come up with ideas of the establishment of the traditional huts at their schools as well as the establishment of Geography centers at the schools. Conduct and team work had an average score of 5 . The teachers, according to the school heads, conducted themselves quite well and as such none among the group had either a misconduct case or a reprimand. 


\subsubsection{Teachers`Involvement in Extra Curricula Activities}

Respondents were asked if the teachers were teachers were effectively involved in extra curricula activities. Responses show that the majority of these teachers undertook duties as sports directors, trainers. Their performance at cluster, district, provincial and national level bears testimony of the level of commitment of the teachers in the different extracurricular disciplines. Some 10 teachers had repeatedly won accolades won at competitions form cluster, district, provincial and national levels.

Documentation and accolades to that effect proved that the teachers were indeed involved in cocurricular activities. In terms of documentation, teachers had gone ahead to prepare for the activities that they undertook as co-curricular activities. Activity plans were available and all participants in the activities were listed and their attendance recorded.

\section{CONCLusions}

From the findings presented above, it can be noted that there is acceptance among respondents that the theory taught to the ODL student teacher is being put into practice as shown by the general classroom practices exhibited by the teachers in question. There are also positive sentiments about ODL Diploma students on the thoroughness in the general classroom management of their work which is enhanced by frequent visits by senior teachers at their individual schools of work and Teaching Practice visits by ZOU lecturers. The documentation by the same teachers is up to scratch especially in scheming which is compulsory in all schools and this has been necessitated by the visits by senior school authorities and lecturers from ZOU which help in many ways in improving scheming, planning lessons and evaluation. It is also noticed that most teachers are able handle their lessons effectively as seen in narrative reports that spoke so well on lesson introductions, teaching strategies, instructional media use and concept and skills development. Despite the fact that most of the ZOU trained teachers were treated as temporary teachers, most of the teachers were involved in the administration of schools in various capacities such as Acting Deputy school heads, acting Teacher in charge (Infants) and Acting Senior Teachers. This was testimony to the effectiveness of the modules that they had covered on general administration. The majority if the teachers were also effectively involved in extra curricula activities with the majority of these teachers undertaking duties as sports directors, trainers and some have won accolades in different activities. Therefore, it came as no surprise as most heads of schools have rated ODL graduates highly on dimensions such as attitude, creativity, problem solving and knowledge of job requirements.

\section{RECOMMENDATIONS}

In light of the above conclusions, it is recommended that:

- ZOU trained teachers need to be deployed to areas where their services are needed in light of their experience of teaching practice.

- Some teachers should be equipped with the necessary basic resources for them to have some start up as they are already resourceful.

- There is need for the acceptance of these students as qualified teachers who are almost the same or even better than those from conventional training institutions because of the theory taught the ODL student teacher

- Since the ODL Diploma holders are thorough in the general classroom management, they should be used as resource persons in the clusters where they are stationed because they are rated high in dimensions such as attitude creativity, problem solving and knowledge of job requirements.

- Most of the ODL trained teachers should be promoted into the administration of schools in various capacities such as Acting Deputy school heads, acting Teacher in charge (Infants) and Acting Senior Teachers.

\section{REFERENCES}

[1] Adams, J., \& DeFleur, M. (2005). The acceptability of a doctoral degree earned online as a credential for obtaining a faculty position. The American Journal of Distance Education, 19(2), 71-85. 
[2] Basaza, G.N., Milman, N.B and Wright, C.R (2010). The Challenges of Implementing Distance Education in Uganda: A Case Study, The International Review of Research in Open and Distance Learning, Vol 11 No. 2.

[3] Carnevale, D. (2005, September 23). Employers still prefer traditional degrees over online learning, study finds. The Chronicle of Higher Education: Information Technology, 52(5), A43.

[4] Carnevale, D. (2007). Employers often distrust online degrees: Some say they prefer job applicants who earned diplomas the old-fashioned way. The Chronicle of Higher Education, 53(18), A28.

[5] Chaney, E. G. (2002). Pharmaceutical employers' perceptions of employees or applicants with e degrees or online coursework. (Doctoral dissertation, Indiana State University, Indiana, USA). Retrieved 9 April, 2011, ProQuest Digital Dissertations database

[6] Dede, C. (1996). Emerging technologies and distributed learning. American Journal of Distance Education, 10(2), 4 -36.

[7] Flowers, J. C. \& Baltzer, H. (2006). Hiring Technical Education faculty: Vacancies, criteria, and attitudes toward online doctoral degrees. Journal of Industrial Teacher Education 43(3).

[8] Guendoo, L. (2007). Credibility challenges to online doctoral graduates seeking faculty positions: A community college perspective. Doctoral dissertation, Capella University Minnesota, USA. Retrieved January 20, 2016, from Dissertations \&Theses: A\&I database.

[9] Gunnell, N. (2010). What are the Objections to Distance Learning? Retrieved from http://www.thefreelibrary.com/Disadvantages+of+Distance+Learning-a01074024279 on 20/04/2011.

[10] Mubika, A.K \&Bukaliya, R. (2014). ODL Graduates in Management: Issues and Challenges from the Subordinate's Perspective International Journal of Research in Business Studies and Management Volume 2, Issue 1, January 2014, PP 23-30 ISSN 2394-5923 (Print) \&ISSN 2394-5931 (Online) Pg 23-30

[11] Russell, T. L. (2001). The no significant difference phenomenon: A comparative research annotated bibliography on technology for distance education. Raleigh, NC: North Carolina State University.

[12] Seibold, K. N. (2007). Employers' perceptions of online education. (Doctoral dissertation, Oklahoma State University, Oklahoma, USA). Retrieved 17 April, 2011, from ProQuest Digital Dissertations database. (Publication No. AAT 3274545).

Citation: Mubika, Augustine, K., Richard Bukaliya. "Dispelling the Myths about the Effectiveness of the Zimbabwe Open University Primary School Trained Teacher in the Instructional Process: Echoes from the Frontline". International Journal of Humanities Social Sciences and Education (IJHSSE), vol 5, no. 2, 2018, pp. 1-8. doi: http://dx.doi.org/10.20431/2349-0381.0502001.

Copyright: (C) 2018 Authors. This is an open-access article distributed under the terms of the Creative Commons Attribution License, which permits unrestricted use, distribution, and reproduction in any medium, provided the original author and source are credited. 